\title{
A Novel Preparation Method for Lean Duplex Steels
}

\author{
Michael Panzenböck, * Katharina S. Ragger, * Harald Chladil, ** and Helmut Clemens * \\ * Department of Physical Metallurgy and Materials Testing, Montanuniversität Leoben, Austria \\ ** Andritz Ltd., Graz, Austria
}

Within many areas of the chemical, power and paper industry as well as in oil and petrol production high corrosion resistant steels are used. It is well known that chromium is the key element to enhance the resistance against corrosion attack. Additional alloying elements like nickel, molybdenum, manganese and/or nitrogen are used to change the lattice structure and to improve mechanical and/or chemical properties. During the last years the commodity price of nickel and molybdenum is significantly increased. Consequently, steels with low nickel and molybdenum content have been developed. The so-called lean duplex steels like LDX 2101 (X2CrMnNiN22-5-2) and SAF 2304 (X2CrNiN23-4) are a good substitute for high alloyed austenitic stainless steels.

In order to obtain information about the microstructural changes of lean duplex steels after a heat treatment at $475^{\circ} \mathrm{C}$ and $700{ }^{\circ} \mathrm{C}$, which has a great influence on mechanical and chemical properties [1], a new preparation method based on [2] has been developed. First attempts, however, have led to unsatisfying results as depicted in Fig 1. Austenite and ferrite are distinguishable, but grain boundaries within the individual phases are not clearly visible. Unfortunately, scanning electron microscope (SEM) observations show deformation pattern (Fig. 2). Such a surface condition does not allow for any electron back scatter diffraction (EBSD) investigations. The newly developed preparation method listed in Tab. 1, in combination with electrolytic etching, gives a very clear identification of the austenite and ferrite phases as well as their grain boundaries (Fig. 3a, b).

Furthermore, this method is also useful to investigate the microstructure after annealing. A heat treatment of these steels at $700{ }^{\circ} \mathrm{C}$ for 30 hours leads to precipitation of carbides and nitrides as well as of $\sigma$-phase. This can be seen from the inserts in Figs. 3a, b. Additionally, a fraction of ferrite is transformed to secondary austenite $\left(\gamma_{2}\right)$. It should be mentioned that this preparation method (Tab. 1) is also suitable for EBSD investigations in order to clarify the different phases after heating (Fig. 4).

TABLE 1. Preparation method for lean duplex steels, " $</<$ " rotating direction of specimen holder and grinding or polishing disk (denotations according to Struers)

\begin{tabular}{|c|c|c|c|c|c|c|}
\hline \multicolumn{7}{|l|}{ grinding } \\
\hline granularity & time $[s]$ & force $[\mathrm{N}]$ & specimens & direction & cooling & rpm \\
\hline 500 & 540 & 70 & 6 & $</<$ & water & 300 \\
\hline 800 & 120 & 70 & 6 & $</<$ & water & 300 \\
\hline 1200 & 90 & 70 & 6 & $</<$ & water & 300 \\
\hline 2400 & 90 & 70 & 6 & $</<$ & water & 300 \\
\hline 4000 & 120 & 70 & 6 & $</<$ & water & 300 \\
\hline \multicolumn{7}{|c|}{ comment: during grinding with granularity 500, the paper was changed every 3 minutes } \\
\hline \multicolumn{7}{|c|}{ polishing } \\
\hline surface & time $[s]$ & force $[\mathbf{N}]$ & specimens & direction & polishing agent & rpm \\
\hline MD Mol. & 480 & 90 & 6 & $</<$ & DP-susp. $3 \mu \mathrm{m}$ & 150 \\
\hline MD Chem. & 600 & 60 & 6 & $>/<$ & $\mathrm{OP}-\mathrm{U}+\mathrm{H}_{2} \mathrm{O}$ & 150 \\
\hline
\end{tabular}

References

[1] K. S. Ragger et al., BHM 9 (2010)

[2] Struers Ltd., Preparation Method of Pure Iron, Information report no. 1829 


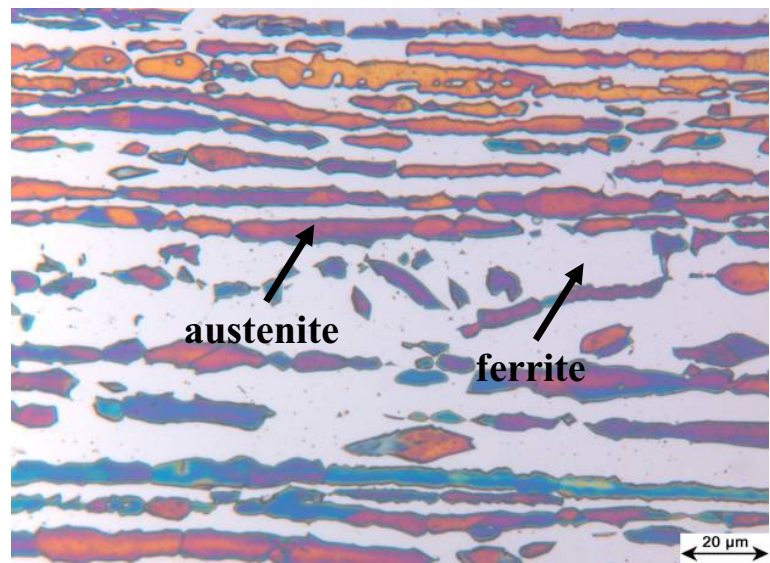

FIG. 1. SAF 2304 after solution annealing and preparation after [2], etching according to "Lichtenegger-Bloech"; light-optical microscopy

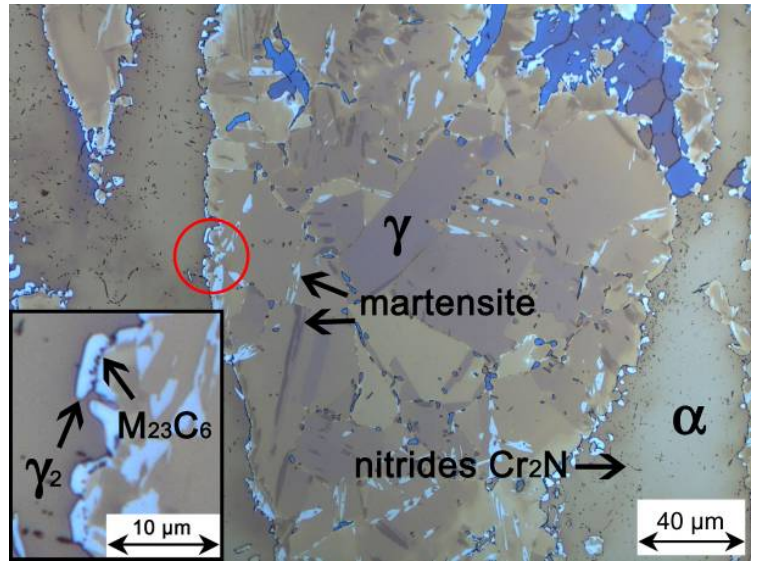

FIG. 3a. LDX 2101 after annealing at $700{ }^{\circ} \mathrm{C}$ for 30 hours, preparation method according to Tab. 1, etching $40 \% \mathrm{NaOH} / 2 \mathrm{~V} / 43 \mathrm{sec}$, light microscopy

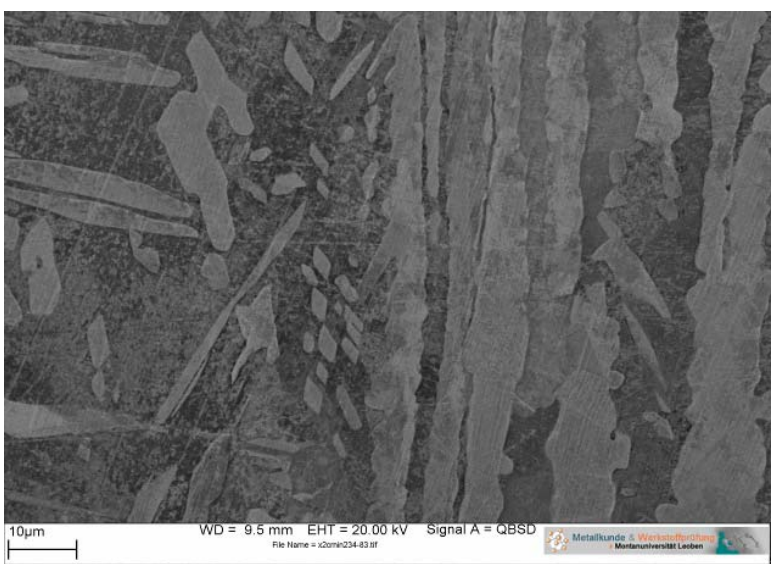

FIG. 2. SAF 2304 after solution annealing and preparation after [2], no etching, SEM investigation; deformation pattern are visible

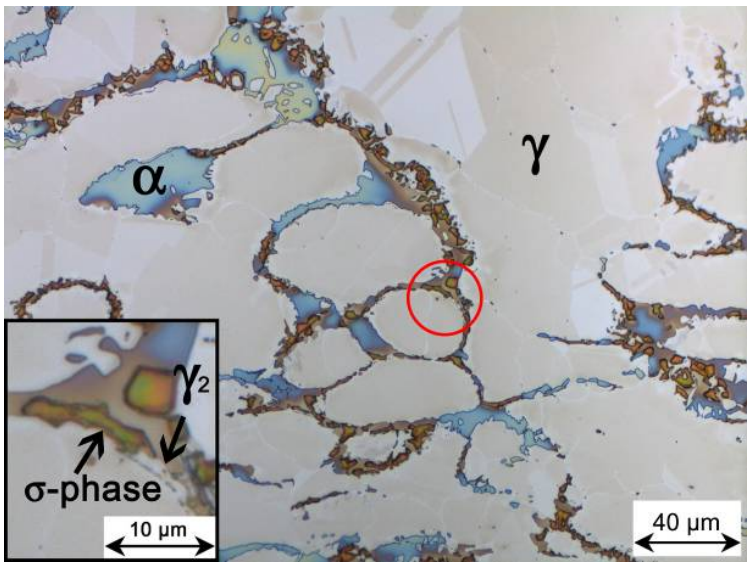

FIG. 3b. SAF 2304 after annealing at $700{ }^{\circ} \mathrm{C}$ for 30 hours, preparation method according to Tab. 1, etching $40 \% \mathrm{NaOH} / 2 \mathrm{~V} / 43 \mathrm{sec}$, light microscopy

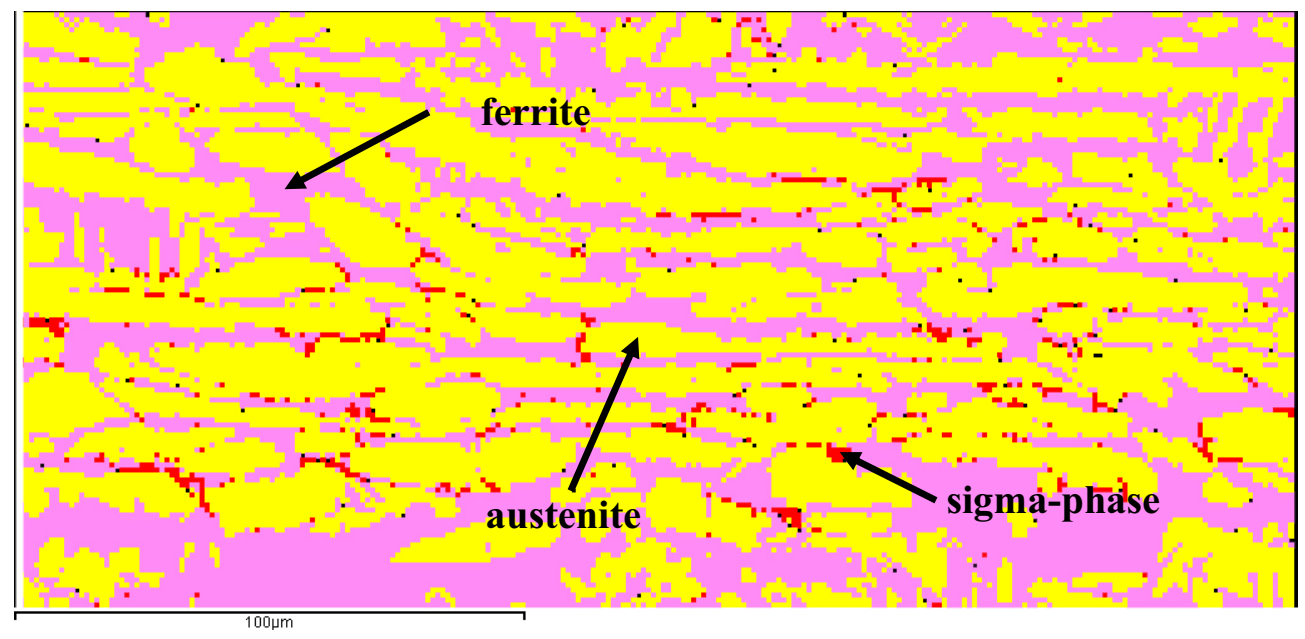

FIG. 4. SAF 2304 after annealing at $700^{\circ} \mathrm{C}$ for 30 hours, preparation method according to Tab. 1, no etching; SEM-EBSD image 